\title{
Vladamir Cacala and the Gelb House (1955)
}

\author{
G. Elliot Reid
}

Eisenman writes of a "modernism of alienation" ${ }^{1}$ which arises in the anxiety of dislocation, an architecture of "an alienated culture with no roots."

"Architecture has repressed the individual consciousness in the physical environment that is supposed to be the happy home. I think it is exactly in the home where the unhomely is, where the terror is alive-in the repression of the unconscious. What I am trying to suggest is that the alienated house makes us realise that we cannot only be conscious of the physical world, but rather also of our own consciousness." 2

I feel that a rootless alienated repression can be a central fact of life in New Zealand, particularly for the exiled immigrant, to which architecture on the whole usually chooses to 'turn a blind eye,' that architecture refuses to engage with a social disintegration and a repression, preferring instead to fragment itself, submerge itself uncritically into its own condition. 
I refer to a work by such an exile, Vladimir Cacala, the Gelb House, Mount Albert (1955). Cacala's work on the whole remained committed to a small circle of influences, choosing to explore a reduced vocabulary of architectural forms. (This alien ground holds no memory, no associative value for Cacala.) The typical Cacala house comprises two enveloping walls with large expanses of glass to the north; planes pushed forward at floor and roof level in the manner of Richard Neutra (for example the Kun house, 1936, or the Davis house, 1937).

Cacala's four years of training at Prague Technical Institute under Svoboda Jiri (who was more recently the set designer for the film 'Amadeus') was in the tradition of a Bauhaus education. His architectural modernism was transplanted in New Zealand with little interest in developing the vernacular shed tradition that Vernon Brown was calling for-his clients were mainly continentals like himself. His only concession would be to the climate, seizing upon the overhang/verandah combination employed in colonial building ostensibly to protect the owners from a harsher summer sun.

Having escaped the communist takeover in 1948 to American-occupied Bavaria, he later made his way to New Zealand where his father already resided, arriving here in 1952. Brenner Associates employed Cacala to develop the furniture design aspect of the company. Vladimir's father had made plywood furniture and his father in turn had been involved with Thonet Mundas, Austria's woodbending manufacturers.

Brenner Associates Ltd. ${ }^{3}$ comprised Stephen Jelicich and Des Mullen (who graduated alongside the Group Architect's members,) John Butterworth, Ron Grant and Milan Mrkusich. Throughout the 1950s these young men had helped to introduce "new overseas ideas in architecture, up-to-date decoration, and the best methods of presenting goods to the public."4 The Herald ran articles on them with lines such as: "A modern Continental type of shop architecture is giving Queen Street a new look and taking some of the drabness from suburban business centres." (6.12.51) A bright, assured and increasingly fashionable mod- 
ernism had moved out of the books, onto the streets and into the homes.

Shortly after he began with Brenner Associates, Cacala received a commission to design the Gelb house. Ilse and Ernst Gelb were an Austrian immigrant couple who had come to New Zealand in $1939.5^{5}$ Both were interested in contemporary European architecture and were impressed by the distinctive and sophisticated ideas of Cacala, whom they had met through friends. They were looking for a private house which would embrace the distant views from their hillside section.

Traversing a rather large series of generalisations, I believe that Cacala's work has been ignored up to this point ${ }^{6}$ because of the condition of normalcy it appears to represent, the easy success with which it meets an unassuming brief. Cacala seems to be questioning how an individual might cope with the New Zealand conformity. Interest in the house eventually focuses on the interior, where originally Milan Mrkusich's fashionable colour scheme helped define the spaces, bold panels of sunset red and aqua combining with the texture of wood. The exterior, particularly as it addresses the road, is about denying interest. One would struggle to call the Gelb house radical in terms of what had already come before. Its very modernism seems schooled, technically good but limited, even off the pace. However, it is this apparent 'normalcy' I wish to question, for within the normal lies something less palatable, less simple and wholesome that one might initially not notice.

Set back slightly below the level of the road, the entrance elevation is unremarkable save for the careful attention to the fenestration, and the flat roof visible from the road. The house is entered either from the garage below or across a small bridge to the front door. Inside, the landing gives access to the kitchen hard left, living area straight ahead, stairs to the basement off to the right and around the corridor, bedrooms, bathroom and a separate toilet. The north elevation is more remarkable. The deck cantilevers beyond the basement and is protected above by an "eyebrow". Although Cacala speaks of the cantilever as an economi- 


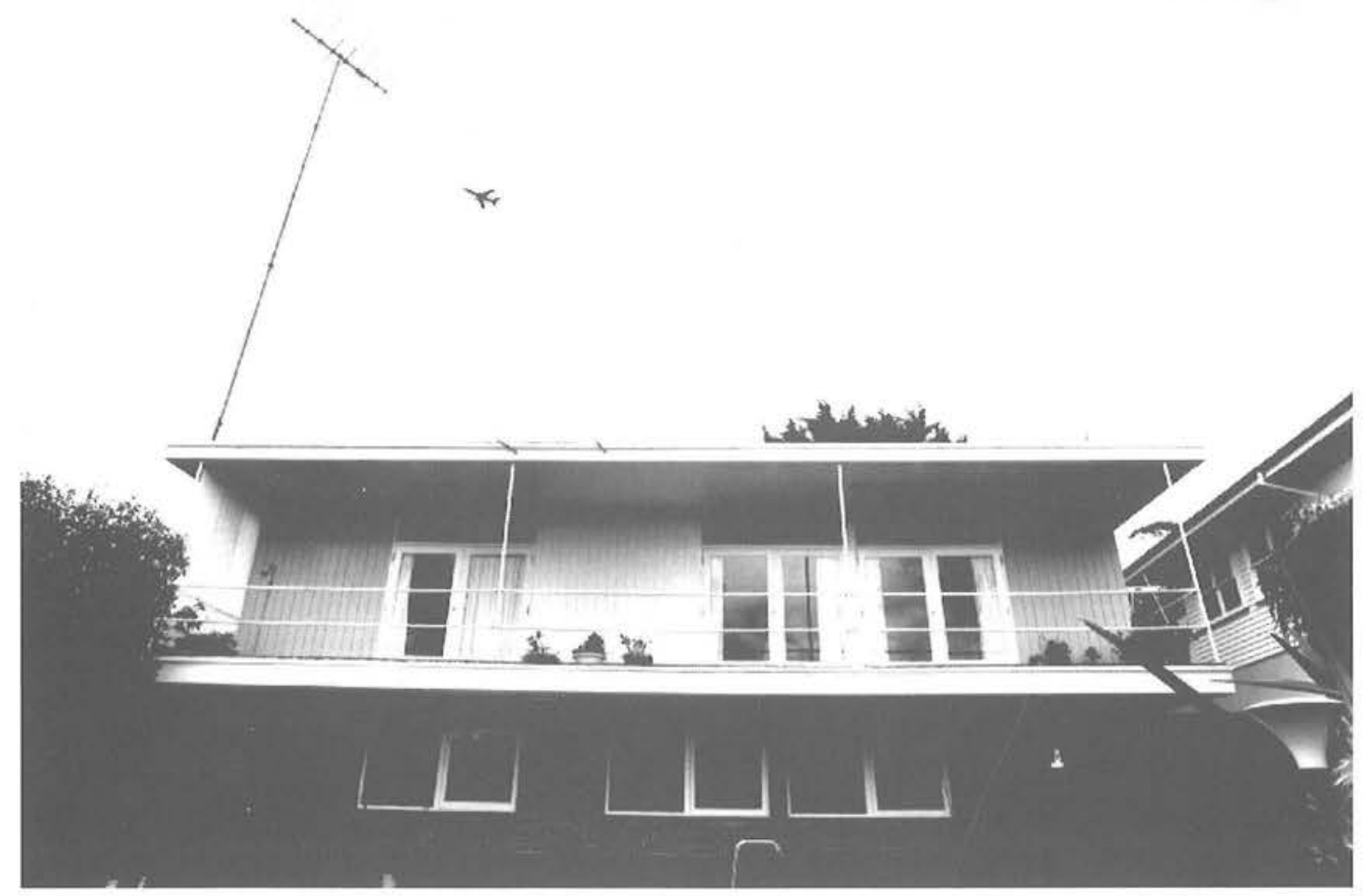

cal device, saving on the basement by tying the deck back to the building with extended joists, there is little doubt it is also a favoured aesthetic feature, expressing lightness in place of the traditional massing of masonry. The north facade makes a false gesture to confidence; blinkered at the sides, the house is like a camera posed towards a distant view. And like a camera the Gelb house could be set up anywhere else, in any country, to any view. This balcony lacks a definitive social purpose. One might stand on it, but would one lounge on it, eat or sleep under its overhang? Its actual dimensions preclude normal activities. Its purpose as such is more gestural. The balcony does not define security but more a state of siege. While one cannot ignore the exterior, nor can one really occupy it.

In the interior a number of subtle relationships are slightly distorted or erased. The absence of the hearth is notable from the start, an elaboration of what had been a central preoccupation in the work of Brenner Associates, into oblivion. In the Jelicich House, Meadowbank $(1956 / 57)$ an enormous fireplace is located at the centre of a nine-square plan. Architecture enshrines the fireplace not only as the physical but also the communal core of the dwelling 


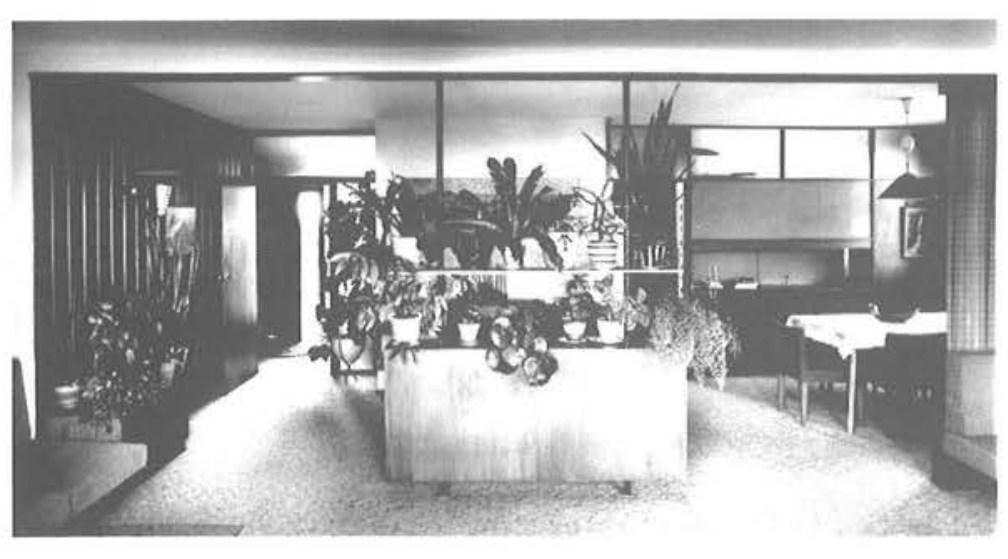

is a long wall-mounted cabinet with radio speakers.

Two black painted steel columns rise through the drinks cabinet and shelf, to support the ceiling's only visible beam. Surprisingly this centrepiece support was introduced at the last moment. The beam that runs through the room was unsupported in the architect's designs; excessive deflection was observed during building. This display of load and support expressing the construction of the house is exceptional for Cacala. His interiors are usually more abstract and devoid of beams. Demonstrating the typical concerns of the furniture designer, he speaks instead of surface textures, uncluttered distinction in joints between one surface and another, transparencies, and interior units, shape of furniture and effect of colour.

The conversation area is a peculiar grouping of furniture to which I will return shortly. The Gelbs' own a coffee table with a glass

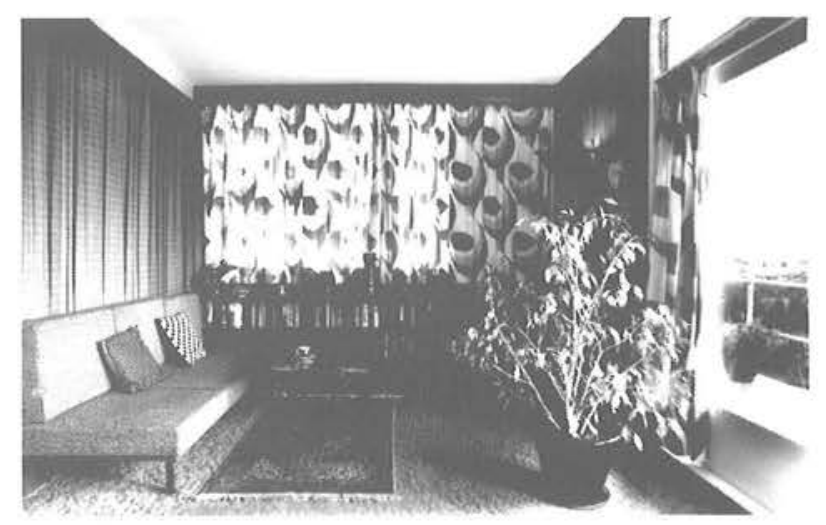
top and reversible yellow / orange base by Bob Roukema, the Dutch designer who produced work for Jon Jansen. (Other versions exist, one by Cacala had disc-topped legs, another by and the subordination of the individual to the family ethos. Semper conferred on the fireplace connotations of sustenance and supplication. If we read it in this material tradition then, without a fireplace the Gelb House becomes spiritually decentred. Solidity is replaced by a peculiar centre-piece drinks cabinet structure behind which 
Des Mullen had wrought iron legs.) A Roukema chair and two by Cacala also feature. These consistently appeared in Brenner advertisements and are made of Japanese Sen with foam rubber and originally were covered in Bedford upholstery. The legs have an elegant precision to their tapered form, though two pins have replaced the former one in connecting the hind leg to the back, stabilising the chair's initial tendency to wobble. A more formal version with a higher back has been placed near the reading area.

The long wall-mounted cabinet with radio speaker, and the built-in couches demonstrate Cacala's European concern with designing almost every piece of furniture in the house. The cabinet itself reflects the building on a minor scale.

The first floor's "in-line" planning allows both main bedroom and living area privileged amounts of sun. The deck's overhang allows the lower winter sun to stream in whilst designed to cut out the high mid-day summer sun. This sun however causes problems in the kitchen, where internal blinds have proved ineffective against the heat.

The prescribed hillside view is framed matter-of-factly by two pairs of glass panelled doors. But the built-in and fixed seating is strangely displaced to the periphery of view. The area before these vast doors, over-lit by the sun, is indeterminate, under-designated, unoccupied. Habitation is removed to a more subdued place, out of the light, out of the frame and is turned by stages away from the exterior world. A hierarchy of seating evolves, as a hierarchy of removal which is further complicated by a third person, who, entering the space, is immediately cast in the role of 'intruder'. Thus an inward gaze, the averted gaze which the interior determines, and the gaze of domination from the exterior, reside side by side. Colomina writes that:

"Architecture is not simply a platform that accommodates the viewing subject. It is a viewing mechanism that produces the subject. It precedes and frames its occupant." 7 
If, by comparison, we take the work of Heinrich Kulka, in the Villa Kantor at Jablonec (193334) where seating patterns lie along or create lines, ${ }^{8}$ one can see how the seated figure is privileged and given access/axis to the view, and a standing figure is denoted as an interloper, interrupting the subject/object (seated viewer/view outside) relationship. In the Kulka House at St Heliers (1944) a series of theatre boxes are established which also construct the subject, positioning the viewer to explore the exterior from the comfort of enclosed space, past an organised 'forecourt' to the chaotic world beyond. Colomina ${ }^{9}$ is dismissive of Kulka in this respect. She reads his interpretation of the theatre box as an exigency of economic planning (tightness and openness) contrasting it with Adolf Loos's understanding of the Raumplan.

"For Loos the theatre box exists in the intersection between claustrophobia and agoraphobia ... on the threshold of the private ... ."10

But for Kulka she claims they speak of the inability of the house to maintain its veil of security. Goldie too notes this difference between Kulka and Loos, although he appears to place a more positive value on the notion of the house as defensible mechanism.

"Knowing that a small, low nook (or recess or annexe) gives the feeling of mental shelter and appears as a place of contemplation; but only if it is a part of a larger room; as for example a box at the theatre which, by itself would give a feeling of claustrophobia."11

The interior of the Gelb house does not ascribe to these conventions of intimacy but, rather to a concept of removal. Comfort is no longer a given condition. The withdrawal of simple comfort calls one to reconstruct it in the mind. In this respect, Cacala the exile is distanced from a Utopian concept of reintegration of the individual and society.

Owners often experienced initial problems in these modern houses. The builder and Cacala had many difficulties, especially with the detailing. Cacala's attempts to reduce the size of interior skirtings, scotias, cornices and window sills ran counter to a building industry still 
accustomed to hiding poor joints behind elaborate dressing; antithetical to modernism's purist streak. Other problems existed. Ilse complained that the mahogany wall initially installed looked like flooring so it was replaced and given a lighter finish. When the wind blew from the north in summer time, the french doors had to be shut, turning the house into an oven. Louvres were installed later, and some picture windows replaced by top hung sashes. When the original cedar overhang got fungus, it had to be painted, with holes bored to allow air to circulate between the ceiling and roof. Yet the Gelbs were prepared to put up with the "new ideas", saying that the "original ones had to suffer." They judge the house has been a success; the architect reconciling his aesthetic concerns with the client's specific needs. An elegant, pleasant and modern home.

What is at stake here, I believe, in reappraising this fragment of New Zealand modern architecture is to witness a simultaneous growth and decay, a sort of minor catastrophe of home and homelessness, a crisis injected just under the skin of architecture, an issue of anxiety and dislocation which was tackled to effect by one architect at least in the post-war period. If New Zealand subjectivity is shaped in its suburbs, defining this country's values, the way people act, dress and discuss things (or don't), it has little to do with angst, more to do with retentive banality; being straight-up, abrupt, but not without edge. Whether Cacala's work is symptomatic or critical of New Zealand suburbia is perhaps moot, nevertheless the concerns discussed here remain relevant and their examination is ongoing.

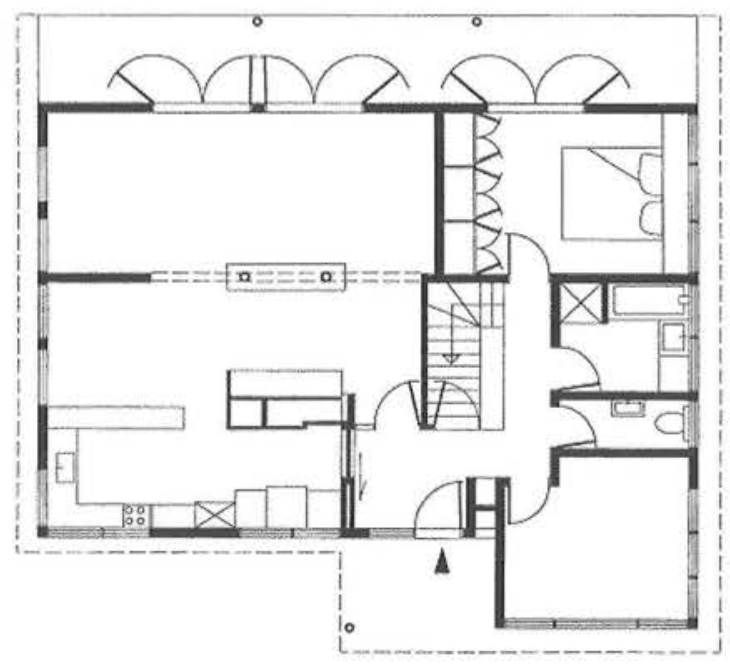

GROUND FLOOR PLAN 


\section{Notes:}

Peter Eisenman-An Architectural Design Interview with Charles Jencks, Architectural Design 58, No. $3 / 4$ (1988), p. 49.

Ibid., p. 52.

Brenner Associates Ltd. Refer to G. Elliot Reid, "Untitled: The Mrkusich House 1950-52", Art New Zealand, No. 62, pp. 79-81 \& 86.

"Trading optimism in Auckland's Queen St." Freelance Magazine, (undated.)

The lack of cultural recognition given to war refugees is both notable and dismal, especially in relation to their experience of this country as opposed to the trite praise of the contribution they made - that is, what we took from them.

A notable exception is Peter Shaw, New Zealand Architecture from Polynesian Beginnings to 1990 (Hodder and Stoughton, 1991), p. 165.

Beatriz Colomina, Sexuality and Space (Princeton: Princeton Architectural Press, 1992), p. 83.

Jan Sapák, "Heinrich Kulka Villa a Jablonec 1933,1934", Domus 726.

Beatrix Colomina, op. cit., p. 76.

Ibid., p. 82.

C.R.Goldie, "Henry Kulka," Undergrad Thesis, Architecture Dept., University of Auckland, (1986). 
